DOI: $10.1002 /(($ please add manuscript number $))$

Article type: Communication

\title{
Deformation of mesoporous titania nanostructures in contact with $D_{2} \mathrm{O}$ vapor
}

Lin Song, Monika Rawolle, Nuri Hohn, Jochen S. Gutmann, Henrich Frielinghaus, and Peter Müller-Buschbaum*

Dr. L. Song, Dr. M. Rawolle, N. Hohn, Prof. P. Müller-Buschbaum

Lehrstuhl für Funktionelle Materialien, Physik-Department, Technische Universität München. James-Franck-Str. 1, 85748 Garching, Germany.

E-mail: muellerb@ph.tum.de

Prof. J. S. Gutmann

Fakultät für Chemie, Physikalische Chemie\& CENIDE, Universität Duisburg-Essen, Universitätsstr. 5, 45141, Essen, Germany

Dr. H. Frielinghaus

Jülich Center for Neutron Science (JCNS) at Heinz Maier-Leibnitz Zentrum (MLZ), Forschungszentrum Jülich GmbH, Lichtenbergstr. 1, 85748 Garching, Germany

Keywords: titania nanostructure, infiltration, backfilling, structure deformation, GISANS

Abstract:

For many applications, mesoporous titania nanostructures are exposed to water or need to be backfilled via infiltration with an aqueous solution, which can cause deformations of the nanostructure by capillary forces. In this work we compare the degree of deformation caused by water infiltration in two types of mesoporous, nanostructured titania films exposed to water vapor. The different types of nanostructured titania films are prepared via a polymer template assisted sol-gel synthesis in conjunction with a polymer-template removal at high-temperatures under ambient conditions versus nitrogen atmosphere. Information about surface and inner morphology is extracted by scanning electron microscopy and grazing incidence small-angle neutron scattering (GISANS) measurements, respectively. Furthermore, complementary information on thin film composition and porosity are probed via x-ray reflectivity. The backfilling induced deformation of near surface structures and structures inside the mesoporous titania films is determined by GISANS before and after $\mathrm{D}_{2} \mathrm{O}$ infiltration. We observe that the respective atmosphere used for template removal influences the details of the titania nanostructure and strongly impacts on the degree of water induced deformation. Drying of the films shows reversibility of the deformation.

Over the last decades mesoporous titania has gained considerable research interest for applications in catalysis, photovoltaics and rechargeable lithium-ion batteries. ${ }^{[1-6]}$ The great success is closely related to its superior chemical stability, large surface-to-volume ratio, tunable 
pore size, and having a wide bandgap. ${ }^{[7-11]}$ In the wake of continued development and advances in the preparation and modification routines, mesoporous titania maintains its important role in the aforementioned fields. For example, due to a Schottky barrier between titania and noble metals, Pt, Au, Pd and/or Ag doped mesoporous titania showed an enhanced photocatalytic activity. ${ }^{[12-15]}$ By fabricating mesopores with large size and/or introducing superstructures with well-defined structural order, modified mesoporous titania photoanodes gave better performance in photovoltaic applications. ${ }^{[16-19]}$ Doping mesoporous titania with metal and/or nonmetal is labeled as an emerging technology for producing anode materials of lithium ion batteries. These dopants can dramatically improve the electrical conductivity of mesoporous titania. ${ }^{[20-22]}$ In all mentioned applications, capillary forces occur during the manufacturing process as a result of infiltration with a liquid into mesopores sometimes called backfilling. Backfilling induced deformation of nanostructures is often found to cause an alteration of the respective device performances. Such deformations are not restricted to titania nanostructures but also occur in other systems. For example, Biener et al. demonstrated that dimensional changes of nanoporous gold, which were induced by capillary forces, enabled surface-chemistry-driven actuation. ${ }^{\text {[23] }}$ Grosman et al. reported that deformation of mesoporous silica (SBA-15) had a direct impact on the thermodynamics of nitrogen adsorption. ${ }^{[24]}$ Through theoretical calculations Weissmüller et al. showed that the strain deriving from capillary forces in nanoporous solids is closely linked to the nanostructure geometry. ${ }^{[25]}$ Nevertheless, all these studies focused on surface-induced deformations, while studies on bulk-induced deformations are, to the best of our knowledge, not yet existing. As a consequence, the particular deformation of titania nanostructures upon capillary forces caused by water ingression is not well understood.

The present work focuses on unravelling structural changes of mesoporous nanostructured titania films due to capillary forces occurring by backfilling with water and disclosing the difference of structural deformation of near surface structures and structures inside the mesoporous titania films. The mesoporous titania films are prepared via block copolymer assisted sol-gel synthesis using the diblock copolymer polydimethyl siloxane-block-methyl methacrylate polyethylene oxide (PDMS-b-MA(PEO)). Such block copolymer templating was shown to allow for obtaining interconnected titania networks with a tunable nanostructure and mesopore size. ${ }^{[16,26-29]}$ In the context of structure deformation, two types of mesoporous titania films are compared to probe the influence of the annealing atmosphere. Grazing incidence small-angle neutron scattering (GISANS) measurements are used to quantify the structural changes induced by capillary forces due to infiltration with $\mathrm{D}_{2} \mathrm{O}$ from its vapor atmosphere. We use $\mathrm{D}_{2} \mathrm{O}$ to have a strong neutron scattering contrast with titania. From the analysis of the GISANS data we detect structural changes of the mesoporous titania inside the films and compare this with the near surface parts for the first time.

In more detail, we prepare two mesoporous nanostructured titania films annealed at $600{ }^{\circ} \mathrm{C}$ in air and in nitrogen atmosphere, which are denoted as air-600 and nitrogen-600, respectively. By the high-temperature annealing the block copolymer template is completely removed. The surface nanostructures of both films are probed with scanning electron microscopy (SEM) as shown in Figure 1a and 1b. Both samples exhibit a mesoporous and interconnected titania network, suggesting that the annealing atmosphere hardly affects the general formation of a sponge-like surface morphology. Moreover, the pore sizes in both films are similar but the regularity of the mesopore arrays differs in terms of order and polydispersity of the pores. The air- 600 film shows an array of well-ordered mesopores with a diameter of $(21 \pm 4) \mathrm{nm}$ (Figure 1a), whereas comparatively less ordered mesopores are present at the nitrogen-600 sample surface and a pore 
size of (18 \pm 7$) \mathrm{nm}$ is observed (Figure 1b). The different structural order can be explained by oxygen vacancies. The annealing at a high temperature in an oxygen-poor environment is known to lead to the formation of more oxygen vacancies,${ }^{[30,31]}$ which could result in a certain degree of distortion of the surface lattice. ${ }^{[32]}$

The vertical composition of the air-600 and nitrogen-600 films is investigated with x-ray reflectivity (XRR). The XRR data with respective fits based on the Parratt algorithm are displayed in Figure 1c. From data modeling, the scattering length density (SLD) profiles are obtained and shown in Figure 1d. It can be seen that both mesoporous titania films consist of two layers: A thin layer with a higher SLD located at the substrate and a thick layer with a lower SLD forming the majority of the film. For the air-600 sample the determined thicknesses are (6.7 $\pm 0.3) \mathrm{nm}$ and $(484 \pm 1) \mathrm{nm}$ for the thin and the thick layer, respectively. Both layers are thicker in the nitrogen-600 film with having a value of $(9.5 \pm 0.4) \mathrm{nm}$ for the thin layer and $(567 \pm 1) \mathrm{nm}$ for the thick layer. Thus, the type of block copolymer removal affects the total film thickness of the mesoporous films. Annealing in nitrogen atmosphere typically leads to a higher percentage of crystal phase (as compared to annealing in air) ${ }^{[33]}$ which reduces the collapse of titania nanostructures during the high-temperature treatment ${ }^{[34]} \mathrm{Ma}$ et al. demonstrated a stable mesoporous structure of films annealed at $450{ }^{\circ} \mathrm{C}$ in nitrogen atmosphere versus a fully destroyed structure of films annealed in air. ${ }^{[33]}$ Moreover, it affects their porosity. In general, the SLD depends on the material density of the probed material. ${ }^{[35-38]}$ Thus, the SLD is reduced for porous films as compared to solid ones. Accordingly, the porosity $\Phi$ of the mesoporous titania films can be calculated as

$\Phi=1-\rho_{\mathrm{m}} / \rho_{\mathrm{t}}$

where $\rho_{\mathrm{m}}$ is the measured SLD of the mesoporous titania films and $\rho_{\mathrm{t}}$ is the theoretical SLD of compact titania $\left(3.17 \times 10^{-5} \AA^{-2}\right)$. For both types of mesoporous titania films, the substrate-near thin layers are found to be much denser as compared to the above-lying thick layers. The thin and thick layers have a porosity of $40 \%$ and $77 \%$ for the air-600 sample, while $37 \%$ and $80 \%$ are calculated for the nitrogen- 600 film. Thus, the differences in the mesopore structure on the film surface (seen with SEM) are present inside the titania films as well. However, from the surface structure one would have extracted the opposite porosity underlining the complexity of nanostructure formation.

To probe the inner morphology of the titania nanostructures annealed in the two different atmospheres, GISANS measurements are performed. This advanced scattering technique is a non-destructive method, which probes structures in a range from nanometer to micrometer with a high statistical relevance since the neutron beam has a macroscopic footprint on the probed samples. ${ }^{[35,39-41]}$ In more detail, both films are firstly measured in air to see the difference of the inner morphology. Subsequent GISANS measurements during exposure to $\mathrm{D}_{2} \mathrm{O}$ vapor (after stabilization at $50{ }^{\circ} \mathrm{C}$ for $2 \mathrm{~h}$ ) are used to compare the deformation of the nanostructures caused by water infiltration. Finally, GISANS measurements are conducted in air again after a total drying of both samples. The two dimensional (2D) GISANS data of both the air-600 and nitrogen-600 samples are displayed in Figure 2a-f. The first, second and third column show the results from the aforementioned experimental scenarios, respectively. These 2D GISANS data show very distinct features. As annotated in Figure $2 b$, the direct beam at $q_{y}=q_{z}=0$ is blocked with a beamstop to protect the detector from oversaturation. Above the direct beam and at $\mathrm{q}_{\mathrm{y}}=0$, an intensity minimum is observed which arises from the sample horizon (indicated by dashed line). Furthermore, an intensity maximum is found at $\mathrm{q}_{\mathrm{z}}=0.22 \mathrm{~nm}^{-1}$, which is the specular reflected peak. At this position, the exit angle of neutron beams is equal to the incident angle. 
Between the specular peak and the sample horizon a local intensity maximum at $\mathrm{q}_{\mathrm{z}}=0.16 \mathrm{~nm}^{-1}$ can be found, which is caused by the enhanced diffusing scattering in the Fresnel transmission function at the critical angle of titania. This intensity maximum is called the Yoneda peak. ${ }^{[42]}$ In addition, it is noticeable that the scattering intensity from both samples increases after infiltration of $\mathrm{D}_{2} \mathrm{O}$ into the mesoporous titania films, which is ascribed to the enhanced scattering contrast having $\mathrm{D}_{2} \mathrm{O}$ inside the titania films. The SLDs of air, titania and $\mathrm{D}_{2} \mathrm{O}$ are $0,2.40 \times 10^{-6} \AA^{-2}$ and $6.33 \times 10^{-6} \AA^{-2}$, respectively. Thus, the scattering contrast between titania and $\mathrm{D}_{2} \mathrm{O}$ is higher than that between titania and air. Moreover, for both the air-600 and nitrogen-600 samples, lateral features at $\mathrm{q}_{\mathrm{y}}= \pm 0.18 \mathrm{~nm}^{-1}$ are clearly visible in the first and third column of 2D GIASANS data. In order to investigate the difference of this feature, horizontal line cuts are performed at the Yoneda peak of titania as this peak is material characteristic. ${ }^{[2,43]}$ The obtained horizontal line cuts are displayed in panels $g$ to $i$ of Figure 2 as a comparison of titania nanostructures probed in air, in $\mathrm{D}_{2} \mathrm{O}$ and in air again. For both samples, the curves in Figure $2 \mathrm{~g}$ and $2 \mathrm{i}$ show sharper peaks at $\mathrm{q}_{\mathrm{y}}= \pm 0.18 \mathrm{~nm}^{-1}$ as compared to the curves in Figure $2 \mathrm{~h}$, which indicates worse long-range lateral order of the bulk titania nanostructure during exposure to $\mathrm{D}_{2} \mathrm{O}$ vapor. To gain a quantitative structure information, the horizontal line cuts are fitted in the framework of the Distorted Wave Born Approximation (DWBA), assuming scattering objects with cylindrical shape distributed on a one-dimensional paracrystal lattice with a Gaussian distribution. ${ }^{\text {[4-46] }}$ From data modeling, two domain sizes (form factors) and two center-to-center distances (structure factors) of the titania nanostructures are obtained and summarized in Figure $2 \mathrm{j}$ and $2 \mathrm{k}$, respectively. It is noticeable that both the domain radii and the corresponding center-to-center distances are larger in the air-600 sample than for the nitrogen-600 sample, indicating that annealing under ambient conditions gives rise to larger titania nanostructures than in nitrogen atmosphere thereby causing the higher SLD value. However, the domain radii for both samples stay almost unchanged irrespective of measuring conditions, implying that the ingression and removal of the $\mathrm{D}_{2} \mathrm{O}$ do not affect the size of titania nanostructures.

From data modeling we realize that the most prominent features in the horizontal line cuts (peaks or shoulders in Figure 2g-i) are caused by the structure factors (center-to-center distances) of the large-sized nanostructures. The fitting results show that the center-to-center distances decrease for both samples when exposed to $\mathrm{D}_{2} \mathrm{O}$ vapor, whereas they return to their original values after $\mathrm{D}_{2} \mathrm{O}$ removal. Moreover, the data modeling for the air-600 sample gives a similar center-tocenter distance of $(29.0 \pm 0.5) \mathrm{nm}$ and a similar Gaussian distribution width of $(3.3 \pm 0.1) \mathrm{nm}$ before exposure to $\mathrm{D}_{2} \mathrm{O}$ and after the complete removal of $\mathrm{D}_{2} \mathrm{O}$. In contrast, when measured in $\mathrm{D}_{2} \mathrm{O}$ vapor, the center-to-center distance decreases to $(24.5 \pm 0.5) \mathrm{nm}$ while the Gaussian distribution width increases to $(5.4 \pm 0.1) \mathrm{nm}$. The nitrogen-600 sample has a similar tendency for the center-to-center distances and its corresponding Gaussian distribution widths. However, the absolute values differ. The center-to-center distances are slightly smaller with a value of $(23.5 \pm 0.5) \mathrm{nm}$ before exposure to $\mathrm{D}_{2} \mathrm{O}$ and after a completely removal of $\mathrm{D}_{2} \mathrm{O}$. Measurements during exposure to $\mathrm{D}_{2} \mathrm{O}$ vapor yield a value of $(21.5 \pm 0.5) \mathrm{nm}$. Similarly, the Gaussian distribution width of $(4.4 \pm 0.1) \mathrm{nm}$ before exposure to $\mathrm{D}_{2} \mathrm{O}$ and after a completely removal of $\mathrm{D}_{2} \mathrm{O}$ is slightly larger as compared to the air-600 sample, while the width increases to $(6.0 \pm 0.1)$ $\mathrm{nm}$ during exposure to $\mathrm{D}_{2} \mathrm{O}$ vapor. To conclude, during exposure to $\mathrm{D}_{2} \mathrm{O}$ vapor, the Gaussian distribution of the center-to-center distance gets broader for both films, suggesting less ordered mesopores inside the backfilled titania films. Capillary force induced deformation of existing pores is assumed to be the origin of the observed increase in Gaussian peak width as well as the decrease of center-to-center distances during the exposure to $\mathrm{D}_{2} \mathrm{O}$ vapor (for both types of films). 
However, the degree of deformation varies in both samples. For the air- 600 sample measured in $\mathrm{D}_{2} \mathrm{O}$ vapor, the center-to-center distance decreases by $15 \%$ whereas the corresponding Gaussian distribution is found to increase by $64 \%$ as compared to their initial values before backfilling. For the nitrogen- 600 sample, a decrease by $9 \%$ and an increase by $36 \%$ are found in the centerto-center distance and the corresponding Gaussian distribution width, respectively. Smaller percentages in both decrease of center-to-center distance and increase of the corresponding Gaussian distribution width suggest a lower degree of deformation of the interconnected titania network in the nitrogen-600 sample. The result implies that more ordered mesopores cannot better withstand the water infiltration and that higher porosity does not induce more deformation. Oxygen vacancies mainly account for the observed differences. On the one hand, the presence of oxygen vacancies leads to the atomic rearrangement, which thereby reduces the Ti-O bond lengths and strengthens the Ti-O bonds. ${ }^{[47,48]}$ Naldoni et al. experimentally observed a lattice contraction of $\mathrm{TiO}_{2}$ induced by oxygen vacancies. ${ }^{[49]}$ On the other hand, water molecules tend to be adsorbed on the perfect $\mathrm{TiO}_{2}$ surface rather than on defect sites induced by oxygen vacancies. ${ }^{[50-52]}$ Hugenschmidt et al. demonstrated that the adsorption energy of water on the $\mathrm{TiO}_{2}$ perfect surface $\left(71-90 \mathrm{~kJ} \mathrm{~mol}^{-1}\right)$ is larger than that on the oxygen vacancies (about $53 \mathrm{~kJ}$ $\left.\mathrm{mol}^{-1}\right) .{ }^{[50]}$ Therefore, stronger Ti-O bonds and less interplay between water molecules and sample surface account for less structure deformation for the nitrogen-600 film. Furthermore, this deformation is reversible as the domain size and the corresponding center-to-center distance of large-sized titania nanostructures stay unchanged within the error of the fit when probed initially before backfilling and after the removal of $\mathrm{D}_{2} \mathrm{O}$. In addition, the Gaussian distribution widths of the center-to-center distances are smaller in the air-600 sample as compared to the nitrogen-600 sample irrespective of measuring conditions, which is also manifested in sharper peaks of the horizontal cuts in the air-600 sample versus the nitrogen-600 sample. The smaller Gaussian distribution width indicates the presence of improved order of the mesopores in the whole volume of the air-600 film. Less oxygen vacancies are ascribed to less structural distortion in the film bulk as well. ${ }^{[53]}$

The center-to-center distance and the corresponding Gaussian distribution width for small-sized nanostructures are simply only smaller as compared to the large-sized nanostructures, whereas they show a similar trend in the different measuring scenarios as discussed for the large-sized nanostructures. Thus, findings are confirming derivations made for the case of the large-sized nanostructures and no additional discussion is required for the smaller nanostructures.

To probe the nanostructures at the near surface and at the near substrate interface (close to silicon) in $\mathrm{D}_{2} \mathrm{O}$ vapor environment for both films, evanescent GISANS measurements are performed from the front side and from the substrate side of the samples, respectively. To achieve this, a very shallow incident angle of $0.15^{\circ}$ is chosen for these measurements, which is below the critical angle of the probed materials. The resulting 2D GISANS data are shown in Figure 3a-d. To quantify the difference of the lateral structures in the sample surface and interface for both samples, horizontal lines cuts are performed at the Yoneda peak of titania and shown in Figure 3e and 3f. The cuts and fits are analyzed with the same procedure as described above for the inner film morphology. The center-to-center distance of large-sized nanostructures gives rise to the prominent peaks in horizontal line cuts for both the sample probed at surface and interface as well. For the air-600 film, both the center-to-center distances at the surface and the interface have a similar value of $(28.0 \pm 0.5) \mathrm{nm}$ with a the Gaussian distribution width of (4.5 \pm 
0.1) $\mathrm{nm}$, while for the nitrogen-600 films the titania nanostructures at sample surface have a center-to-center distance of $(23 \pm 0.5) \mathrm{nm}$ with a Gaussian distribution of $(5.3 \pm 0.1) \mathrm{nm}$ and at the sample interface the center-to-center distance has the same size but with a larger Gaussian distribution of $(5.8 \pm 0.1) \mathrm{nm}$. Therefore, for both types of films the center-to-center distance of titania nanostructures at the surface and at the interface is slightly larger as compared to the bulk $((24.5 \pm 0.5) \mathrm{nm}$ for the air-600 films and $(21.5 \pm 0.5) \mathrm{nm}$ for the nitrogen-600 films), whereas the widths of Gaussian distribution are slightly smaller. As a consequence, the nanostructures at the surface and interface of both samples have less distortion in the $\mathrm{D}_{2} \mathrm{O}$ vapor environment as compared to the bulk nanostructures. For the sample surface, it may due to the weak interaction between surface nanostructures and $\mathrm{D}_{2} \mathrm{O}$ vapor; while for the interface it is ascribed to the existence of the denser layer. Moreover, from fitting an additional titania domain size of (70 \pm 9$)$ $\mathrm{nm}$ with a center-to-center distance of $(150 \pm 20) \mathrm{nm}$ is required for modelling the nanostructure at the interface to the substrate for both the air-600 and nitrogen-600 films, which is in line with a denser structural morphology revealed by XRR measurements.

In summary, nanostructured mesoporous titania films are prepared with high temperature treatment in ambient air and nitrogen atmosphere. In general, both films consist of two parts in vertical direction: In a thin layer close to the substrate the film is denser, whereas the main part of the film on top is more porous. The applied preparation process impacts on the titania nanostructure. The nitrogen-600 film shows a larger film thickness and average porosity than the air-600 film, whereas its nanostructure order is less-defined. During exposure to $\mathrm{D}_{2} \mathrm{O}$ vapor, infiltration of water causes distortions of the titania nanostructures, which is an important finding with respect to the applications that making use of backfilling of titania nanostructures from aqueous solution such DSSCs or exposing titania nanostructures to an aqueous environment such as batteries and catalysis. The air-600 film shows a larger degree of structure deformation in the sample bulk as compared to the nitrogen-600 film. Thus, the annealing atmosphere is relevant for the details of the mesoporous nanostructure and perhaps more important also impacts on the level to what the initially tailored nanostructure can be maintained during water infiltration. Keeping in mind that many studies carefully design titania nanostructures to match characteristic needs from the application, such backfilling induced changes of the nanostructures are very relevant and should be considered in the optimization of the titania nanostructures. As compared to the film volume, the surface and interface nanostructures are less affected by the backfilling. Therefore, imaging techniques will underestimate the distortions of the nanostructure induced by water infiltration. Moreover, the deformation of lateral nanostructures is completely reversible after the removal of $\mathrm{D}_{2} \mathrm{O}$ from both samples. Thus, deformation is only present as long as water is present inside the pores. Such water induced reversible nanostructure deformation shows great potential for a possible use of mesoporous titania films as actuator materials. The different demands of the nanoscale actuator can be easily tuned via the atmosphere present during the high temperature removal of the block copolymer template.

\section{Experimental Section}

Materials: Polydimethyl siloxane-block-methyl methacrylate polyethylene oxide (PDMS-b$\left.\mathrm{MA}(\mathrm{PEO}), \mathrm{M}_{\mathrm{n}}(\mathrm{PDMS})=5000 \mathrm{~g} \mathrm{~mol}^{-1}, \mathrm{M}_{\mathrm{n}}(\mathrm{PEO})=3000 \mathrm{~g} \mathrm{~mol}^{-1}\right)$ was synthesized according to a procedure described in literature. ${ }^{[54]}$ Titanium tetra-isopropoxide (TTIP, 97\%), tetrahydrofuran (THF, $99.9 \%$ ), iso-propanol (IPA, $99.9 \%$ ) and hydrochloric acid ( $\mathrm{HCl}, 37 \%)$ were purchased from Carl Roth GmbH. 
Preparation of nanostructured titania films: The nanostructured titania films were fabricated based on a diblock copolymer template assisted sol-gel synthesis. Firstly, the diblock copolymer PDMS-b-MA(PEO) (305 mg) was dissolved in a mixture of THF (3.85 mL) and IPA (1.45 mL) for $30 \mathrm{~min}$ and then filtered with a polytetrauoroethylene (PTFE) filter (a pore size of $0.45 \mu \mathrm{m}$ ). Subsequently, TTIP $(159 \mu \mathrm{L})$ and $\mathrm{HCl}(42.6 \mu \mathrm{L})$ were added simultaneously to the polymer solution. The final weight ratios of the sol-gel components were 6:3:1 of PDMS-bMA(PEO):TTIP:HCl. After 60 min of stirring at room temperature, the solution was spin-coated (2000 rpm, $60 \mathrm{~s}$ ) onto the silicon ( $\mathrm{Si}$ ) substrates. Directly after spin coating the samples were annealed at $600{ }^{\circ} \mathrm{C}$ for $4 \mathrm{~h}$ in an ambient air or nitrogen atmosphere.

Film characterization: SEM measurements were performed on an FESEM Gemini NVision 40 apparatus (Carl Zeiss) with an acceleration voltage of $5 \mathrm{kV}$, an aperture of $10 \mu \mathrm{m}$ and a working distance of $3 \mathrm{~mm}$. XRR measurements were conducted on a Bruker D8 ADVANCE x-ray diffractometer using a wavelength of $1.54 \AA$ with a $2 \theta$ range from 0 to $6^{\circ}$. The GISANS measurements were carried out at the small angle neutron scattering beamline KWS2 of the Jülich Centre for Neutron Science (JCNS) at the research reactor FRM II of the Heinz MaierLeibnitz Zentrum (Garching, Germany). ${ }^{[55]}$ A neutron wavelength of $4.5 \AA$ was chosen by velocity selectors. For inner film morphology probing, a grazing incident angle was set to $0.55^{\circ}$, which was well above the critical angle of titania $\left(0.23^{\circ}\right)$. Before the measurements, the samples were placed in a vapor chamber. After a first GISANS measurement in air, the chamber was closed and $10 \mathrm{~mL}$ of $\mathrm{D}_{2} \mathrm{O}$ were injected in a reservoir inside the chamber. Subsequently, the chamber was heated up to $50{ }^{\circ} \mathrm{C}$. The relative humidity in the chamber was measured to be $80 \%$. After $2 \mathrm{~h}$ stabilization of the $\mathrm{D}_{2} \mathrm{O}$ induced humidity, the samples were probed by GISANS in the vapor environment. Finally, the samples were measured again after being completely dried in air. For each GISANS measurement the data acquisition time was $60 \mathrm{~min}$. For the investigation of the nanostructures near the film surface and near the substrate interface, the evanescent GISANS measurements were performed with a grazing incident angle of $0.15^{\circ}$. To probe the film surfaces, the measurements were conducted from front side of the probed samples. Similarly, the near substrate structures were probed from the substrate side. These measurements were counted 120 min each. To detect the scattering signal, a two-dimensional detector with ${ }^{6} \mathrm{Li}$ scintillator glass (pixel size of $5.25 \mathrm{~mm} \times 5.25 \mathrm{~mm}, 128$ by 128 array) was used with a sample-to-detector distance of $6.661 \mathrm{~m}$ for both types of GISANS measurements.

\section{Acknowledgements}

This work was supported by funding from TUM.solar in the context of the Bavarian Collaborative Research Project Solar Technologies Go Hybrid (SolTech), International Research Training Groups 2022 Alberta/Technical University of Munich International Graduate School for Environmentally Responsible Functional Hybrid Materials (ATUMS) and the Nanosystems Initiative Munich (NIM). L.S. acknowledges the China Scholarship Council (CSC). The authors thank Dr. Maria D'Acunzi for synthesis of the diblock copolymer and Professor Alexander Holleitner and Peter Weiser for the access to SEM measurements.

Received: ((will be filled in by the editorial staff))

Revised: ((will be filled in by the editorial staff)) Published online: ((will be filled in by the editorial staff)) 
[1] A. A. Ismail, D. W. Bahnemann, J. Mater. Chem. 2011, 21, 11686.

[2] X. Wang, L. C. Bai, H. Y. Liu, X. F. Yu, Y. D. Yin, C. B. Gao, Adv. Funct. Mater. 2018, $28,1704208$.

[3] L. Song, W. Wang, V. Körstgens, D. Moseguí González, F. C. Löhrer, C. J. Schaffer, J. Schlipf, K. Peters, T. Bein, D. Fattakhova-Rohlfing, S. V. Roth, P. Müller-Buschbaum, Nano Energy 2017, 40, 317.

[4] M. Abdi-Jalebi, M. I. Dar, A. Sadhanala, S. P. Senanayak, F. Giordano, S. M. Zakeeruddin, M. Grätzel, R. H. Friend, J. Phys. Chem. Lett. 2016, 7, 3264.

[5] K. Wang, M. Wei, M. A. Morris, H. Zhou, J. D. Holmes, Adv. Mater. 2007, 19, 3016.

[6] R. Zhang, A. A. Elzatahry, S. S. Al-Deyab, D. Zhao, Nano Today 2012, 7, 344.

[7] T. Fröschl, U. Hörmann, P. Kubiak, G. Kučerová, M. Pfanzelt, C. K. Weiss, R. J. Behm, N. Hüsing, U. Kaiser, K. Landfester, M. Wohlfahrt-Mehrens, Chem. Soc. Rev. 2012, 41, 5313.

[8] L. Song, W. Wang, V. Körstgens, D. Moseguí González, Y. Yao, N. K. Minar, J. M.

Feckl, K. Peters, T. Bein, D. Fattakhova-Rohlfing, G. Santoro, S. V. Roth, P. Müller-Buschbaum, Adv. Funct. Mater. 2016, 26, 1498.

[9] D. Fattakhova-Rohlfing, A. Zaleska, T. Bein, Chem. Rev. 2014, 114, 9487.

[10] X. Chen, L. Liu, F. Huang, Chem. Soc. Rev. 2015, 44, 1861.

[11] J. Low, B. Cheng, J. Yu, Appl. Surf. Sci. 2017, 392, 658.

[12] H. Li, Z. Bian, J. Zhu, Y. Huo, H. Li, Y. Lu, J. Am. Chem. Soc. 2007, 129, 4538.

[13] J. Schneider, M. Matsuoka, M. Takeuchi, J. Zhang, Y. Horiuchi, M. Anpo, D. W.

Bahnemann, Chem. Rev. 2014, 114, 9919.

[14] A. A. Ismail, D. W. Bahnemann, J. Phys. Chem. C 2011, 115, 5784.

[15] M. Andersson, H. Birkedal, N. R. Franklin, T. Ostomel, S. Boettcher, A. E. C. Palmqvist, G. D. Stucky, Chem. Mater. 2005, 17, 1409.

[16] L. Song, W. Wang, S. Pröller, D. Moseguí Gonzalez, J. Schlipf, C. J. Schaffer, K. Peters, E. M. Herzig, S. Bernstorff, T. Bein, D. Fattakhova-Rohlfing, P. Müller-Buschbaum, ACS

Energy Lett. 2017, 2, 991.

[17] A. Yella, S. Mathew, S. Aghazada, P. Comte, M. Grätzel, M. K. Nazeeruddin, J. Mater. Chem. C 2017, 5, 2833.

[18] Z.-Q. Li, Y. Ding, L.-E. Mo, L.-H. Hu, J.-H. Wu, S.-Y. Dai, ACS Appl. Mater. Interfaces 2015, 7, 22277.

[19] L. Song, A. Abdelsamie, C. J. Schaffer, V. Körstgens, W. Wang, T. Wang, E. D. Indari, T. Fröschl, N. Hüsing, T. Haeberle, P. Lugli, S. Bernstorff, P. Müller-Buschbaum, Adv. Funct. Mater. 2016, 26, 7084.

[20] S. K. Das, S. Darmakolla, A. J. Bhattacharyya, J. Mater. Chem. 2010, 20, 1600.

[21] X. Su, Q. L. Wu, X. Zhan, J. Wu, S. Wei, Z. Guo, J. Mater. Sci. 2012, 47, 2519.

[22] H. Zou, K. Yan, Y. Cong, X. Li, J. Zhang, Z. Cui, Z. Dong, G. Yuan, Y. Li, Res. Chem. Intermediat. 2017, 43, 2891.

[23] J. Biener, A. Wittstock, L. A. Zepeda-Ruiz, M. M. Biener, V. Zielasek, D. Kramer, R. N. Viswanath, J. Weissmüller, M. Bäumer, A. V. Hamza, Nat. Mater. 2009, 8, 47.

[24] A. Grosman, C. Ortega, Phys. Rev. B 2008, 78, 085433.

[25] J. Weissmüller, H. L. Duan, D. Farkas, Acta Mater. 2010, 58, 1.

[26] S. Guldin, M. Kolle, M. Stefik, R. Langford, D. Eder, U. Wiesner, U. Steiner, Adv. Mater. 2011, 23, 3664.

[27] M. Rawolle, M. A. Ruderer, S. M. Prams, Q. Zhong, D. Magerl, J. Perlich, S. V. Roth, P. Lellig, J. S. Gutmann, P. Müller-Buschbaum, Small 2011, 7, 884. 
[28] A. Sarkar, N. J. Jeon, J. H. Noh, S. I. Seok, J. Phys. Chem. C 2014, 118, 16688.

[29] C.-C. Chung, C. S. Lee, E. Jokar, J. H. Kim, E. W.-G. Diau, J. Phys. Chem. C 2016, 120, 9619.

[30] M. C. Wu, K. C. Hsiao, Y. H. Chang, S. H. Chan, Appl. Surf. Sci. 2018, 430, 407.

[31] X. Pan, M. Q. Yang, X. Fu, N. Zhang, Y. J. Xu, Nanoscale 2013, 5, 3601.

[32] X. An, C. Hu, H. Liu, J. Qu, Langmuir 2018, 34, 1883.

[33] Q. Ma, T. P. Qin, S. J. Liu, L. Q. Weng. Y. Dong, Appl. Phys. A 2011, 104, 365.

[34] D. Grosso, G. J. de A. A. Soler-Illia, E. L. Crepaldi, F. Cagnol, C. Sinturel, A. Bourgeois, A. Brunet-Bruneau, H. Amenitsch, P. A. Albouy, C. Sanchez, Chem. Mater. 2003, 15, 4562.

[35] M. Rawolle, K. Sarkar, M. A. Niedermeier, M. Schindler, P. Lellig, J. S. Gutmann, J. F. Moulin, M. Haese-Seiller, A. S. Wochnik, C. Scheu, P. Müller-Buschbaum, ACS Appl. Mater. Interfaces 2013, 5, 719.

[36] K, Wojciechowski, M, Orczyk, T. Gutberlet, T. Geue, Biochim. Biophys. Acta 2016, $1858,363$.

[37] J. D. Yeager, R. Chellappa, S.Singh, J. Majewski, Mater. Today 2015, 3, 1.

[38] J. D. Roehling, C. W. Rochester, H. W. Ro, P. Wang, J. Majewski, K. J. Batenburg, I.

Arslan, D. M. Delongchamp, A. J. Moulé, J. Polym. Sci., Part B: Polym. Phys. 2014, 52, 1291.

[39] T. Salditt, G. Brotons, Anal. Bioanal. Chem. 2004, 379, 960.

[40] S. Ueda, S. Koizumi, A. Ohira, S. Kuroda, H. Frielinghaus, Physica B 2017, DOI: 10.1016/j.physb.2017.12.061.

[41] S. Jaksch, F. Lipfert, A. Koutsioubas, S. Mattauch, O. Holderer, O. Ivanova, H. Frielinghaus, Phys. Rev. E 2015, 91, 022716.

[42] Y. Yoneda, Phys. Rev. 1963, 131, 2010.

[43] S. K. Sinha, E. B. Sirota, S. Garoff, H. B. Stanley, Phys. Rev. B 1988, 38, 2297.

[44] J. S. Pedersen, J. Appl. Crystallogr. 1994, 27, 595.

[45] M. Rauscher, R. Paniago, H. Metzger, Z. Kovats, J. Domke, J. Peisl, H. D. Pfannes, J.

Schulze, I. Eisele, J. Appl. Phys. 1999, 86, 6763.

[46] W. Wang, C. J. Schaffer, L. Song, V. Körstgens, S. Pröller, E. D. Indari, T. Y. Wang, A. Abdelsamie, S. Bernstorff, P. Müller-Buschbaum, J. Mater. Chem. A 2015, 3, 8324.

[47] B. J. Morgan, G. W. Watson, J. Phys. Chem. C 2010, 114, 2321.

[48] A. Janotti, J. B. Varley, P. Rinke, N. Umezawa, G. Kresse, C. G. Van de Walle, Phys.

Rev. B 2010, 81, 085212.

[49] A. Naldoni, M. Allieta, S. Santangelo, M. Marelli, F. Fabbri, S. Cappelli, C. L. Bianchi, R. Psaro, V. Dal Santo, J. Am. Chem. Soc. 2012, 134, 7600.

[50] M. B. Hugenschmidt, L. Gamble, C. T. Campbell, Surf. Sci. 1994, 302, 329.

[51] M. A. Henderson, Langmuir 1996, 12, 5093.

[52] R. Schaub, P. Thostrup, N. Lopez, E. Laegsgaard, I. Stensgaard, J. K. Nørskov, F.

Besenbacher, Phys. Rev. Lett. 2001, 87, 266104.

[53] Y. Wang, C. Sun, X. Yan, F. Xiu, L. Wang, S. C. Smith, K. L. Wang, G. Q. Lu, J. Zou, J. Am. Chem. Soc. 2011, 133, 695.

[54] G. Kaune, M. Memesa, R. Meier, M. A. Ruderer, A. Diethert, S. V. Roth, M. D'Acunzi, J. S. Gutmann, P. Müller-Buschbaum, ACS Appl. Mater. Interfaces 2009, 1, 2862.

[55] A. Radulescu, V. Pipich, H. Frielinghaus, M. -S. Appavou, J. Phys. Conf. Ser. 2012, 351, 012026. 

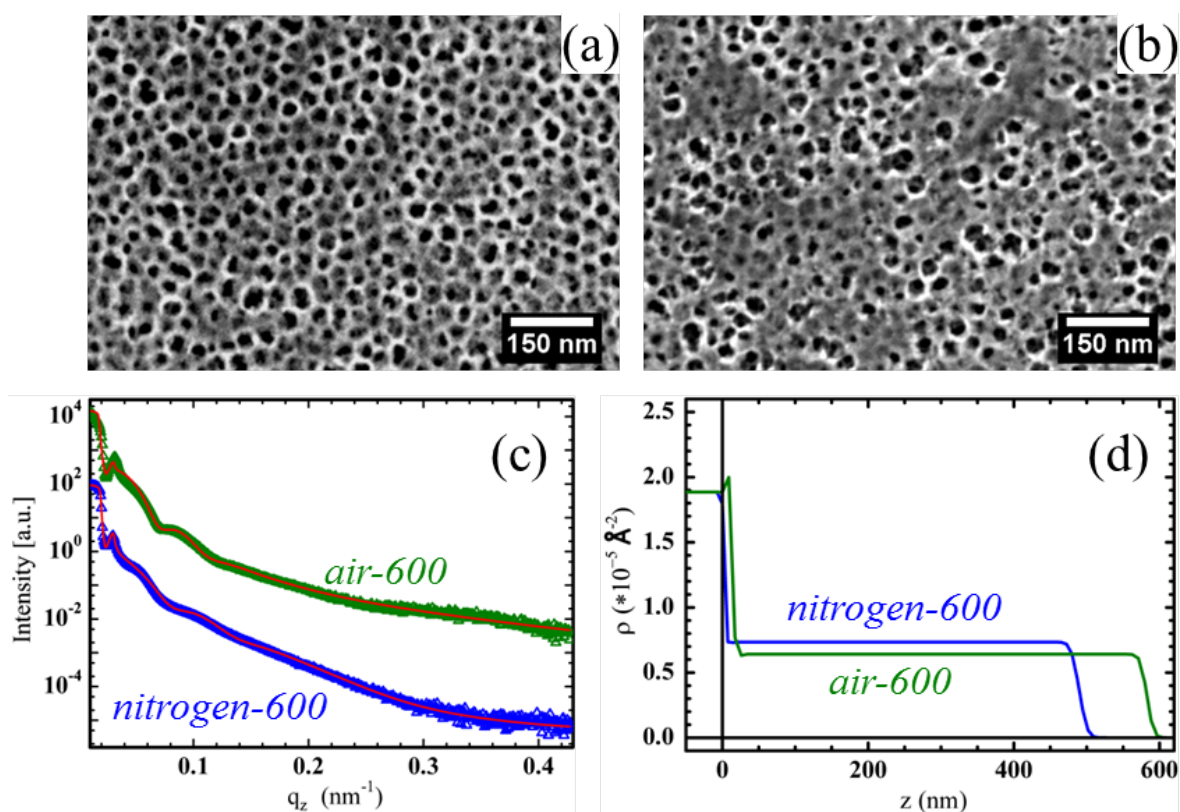

Figure 1. Plan view SEM images for the (a) air-600 film and the (b) nitrogen-600 film. (c) XRR data and (d) the extracted SLD profiles for both samples. The blue and green symbols and lines represent the air-600 and nitrogen-600 films, respectively. In (c), the red lines indicate the fits to XRR data and the curves are shifted along the intensity axis for clarity of the presentation. 

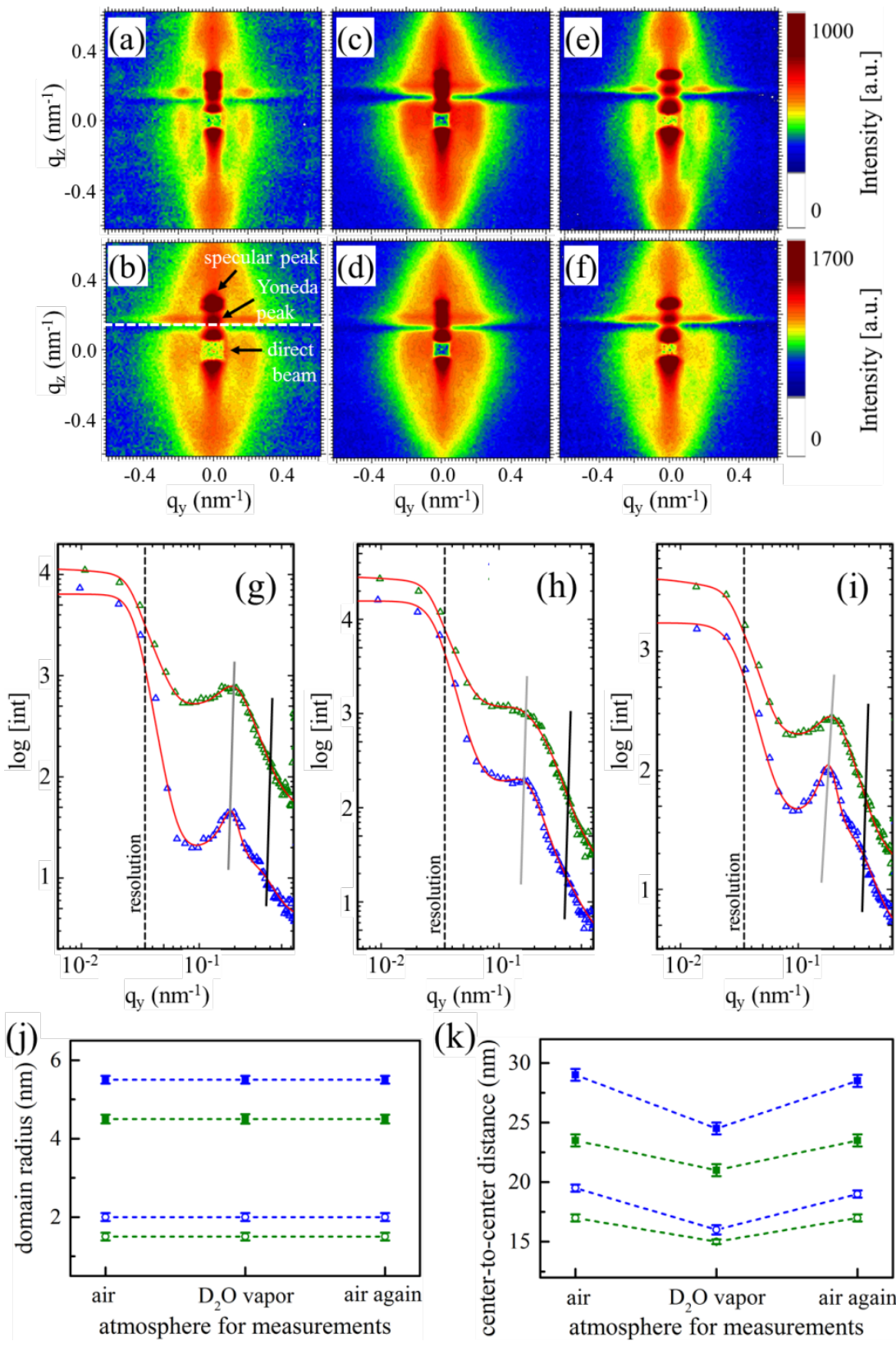

Figure 2. 2D GISANS data of the (a, c, e) air-600 film and the (b, d, f) nitrogen-600 film are shown for $(a, b)$ the initial measurement in air, $(c, d)$ the measurement in $\mathrm{D}_{2} \mathrm{O}$ vapor and $(\mathrm{e}, \mathrm{f})$ the measurement in air after a complete water removal. Horizontal line cuts of 2D GISANS data measured in (g) air, (h) $\mathrm{D}_{2} \mathrm{O}$ vapor and (i) air after water removal. The blue and green symbols represent the air-600 and nitrogen-600 films, respectively. Black and gray vertical lines indicate positions of small- and large-sized structures, respectively. The red lines show the fits to the data. The curves are shifted along the intensity axis for clarity of the presentation. Extracted characteristic length scales from data modeling: $(\mathrm{j})$ domain radii and $(\mathrm{k})$ the corresponding center-to-center distances of titania nanostructure inside both films. The green and blue symbols represent the air-600 and nitrogen-600 films, respectively. Hollow circles and solid squares indicate small- and large-sized structures, respectively. The dashed lines are guides to the eye. 

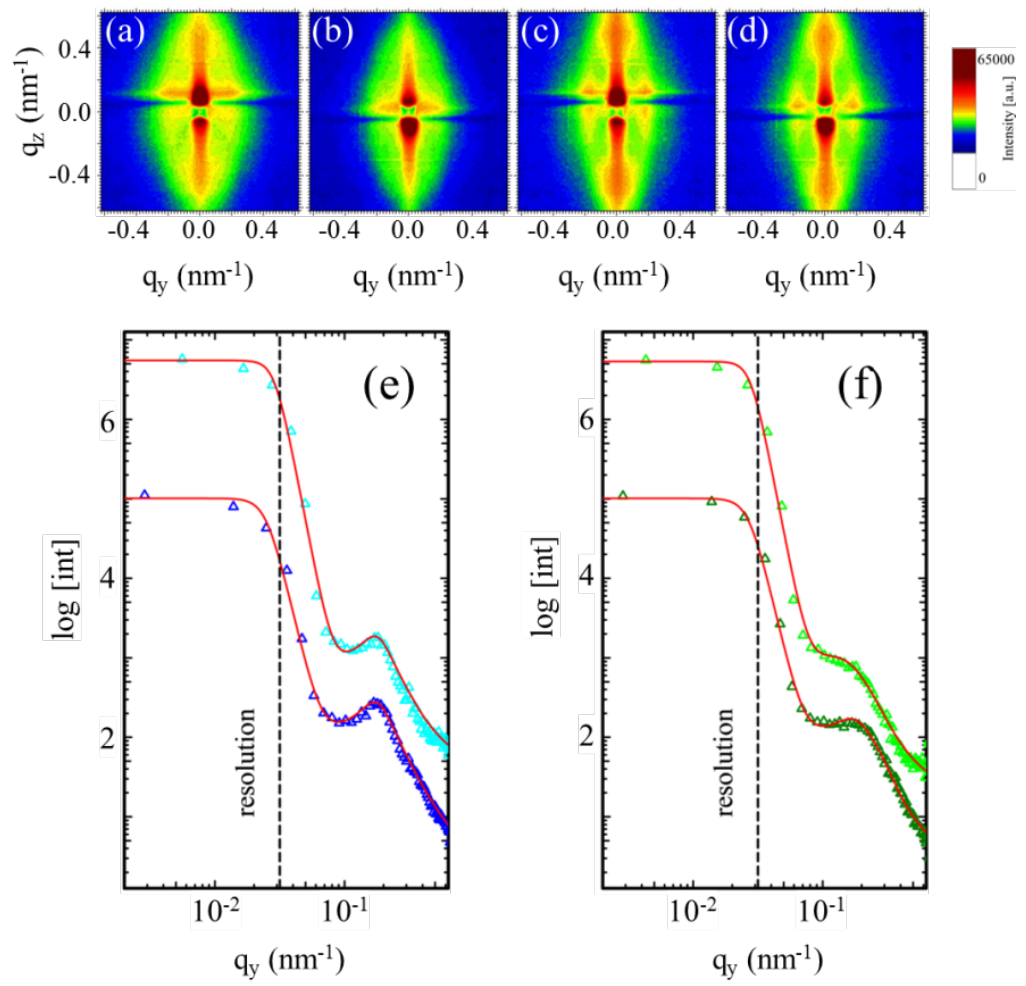

Figure 3. Evanescent 2D GISANS data of mesoporous titania films annealed (a, b) in air and (c, d) in nitrogen atmosphere are shown for the measurements from $(\mathrm{a}, \mathrm{c})$ the sample front side and from $(b, d)$ the substrate side. Horizontal line cuts obtained from the 2D GISANS data of (e) the air-600 and the (f) nitrogen-600 sample. In (e,f) symbols in dark and in light colors represent cuts obtained from the measurements from the sample front side and substrate side, respectively. The red lines are the fits to the cuts. The curves are shifted along the intensity axis for clarity of the presentation. 
The deformation of mesoporous titania films after ingression of $\mathrm{D}_{2} \mathrm{O}$ into mesopores is investigated with grazing incidence small-angle neutron scattering measurements. The degree of the nanostructure deformation depends on the atmosphere present during the high temperature annealing. Moreover, the nanostructures near the film surface, near the substrate interface and in the bulk deform differently. The differences in oxygen vacancies, porosities and surroundings cause the deformation difference.

Keyword titania nanostructure, $\mathrm{D}_{2} \mathrm{O}$ vapor, structure deformation, GISANS

L. Song, M. Rawolle, N. Hohn, J. S. Gutmann, H. Frielinghaus, P. Müller-Buschbaum*

Deformation of mesoporous titania nanostructures in contact with $\mathrm{D}_{2} \mathrm{O}$ vapor

ToC figure

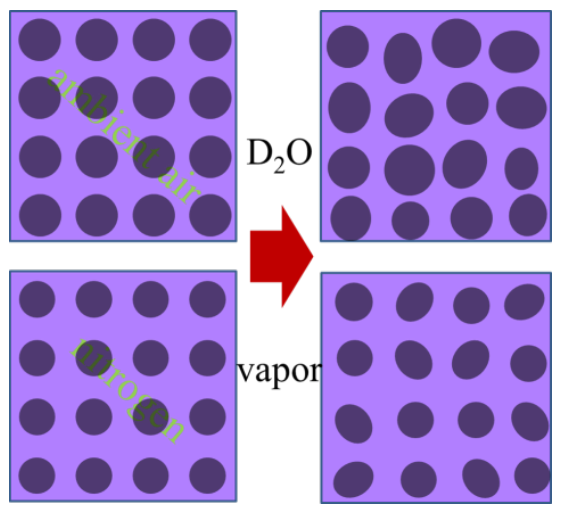

